\title{
ORIGINAL
}

\section{Prevalence and risk factors related to haloperidol use for delirium in adult intensive care patients: the multinational AID-ICU inception cohort study}

Marie O. Collet ${ }^{1,2^{*}} \mathbb{D}$, Jesús Caballero ${ }^{3}$, Romain Sonneville ${ }^{4,5}$, Fernando A. Bozza ${ }^{6}$, Peter Nydahl ${ }^{7,8}$, Anna Schandl ${ }^{9}$, Hilden Wøien ${ }^{10}$, Giuseppe Citerio ${ }^{11}$, Mark van den Boogaard ${ }^{12}$, Johanna Hästbacka ${ }^{13}$, Matthias Haenggi ${ }^{14}$, Kirsten Colpaert ${ }^{15}$, Louise Rose ${ }^{16,17}$, Marija Barbateskovic ${ }^{2,18}$, Theis Lange ${ }^{2,19,21}$, Aksel Jensen ${ }^{2,19}$, Martin B. Krog ${ }^{20}$, Ingrid Egerod ${ }^{1,2}$, Helle L. Nibro ${ }^{2,20}$, Jørn Wetterslev ${ }^{2,18}$, Anders Perner ${ }^{1,2}$ and the AID-ICU cohort study co-authors

\begin{abstract}
Purpose: We assessed the prevalence and variables associated with haloperidol use for delirium in ICU patients and explored any associations of haloperidol use with 90-day mortality.

Methods: All acutely admitted, adult ICU patients were screened during a 2-week inception period. We followed the patient throughout their ICU stay and assessed 90-day mortality. We assessed patients and their variables in the first 24 and $72 \mathrm{~h}$ in ICU and studied their association together with that of ICU characteristics with haloperidol use.

Results: We included 1260 patients from 99 ICUs in 13 countries. Delirium occurred in 314/1260 patients [25\% (95\% confidence interval 23-27)] of whom 145 received haloperidol [46\% (41-52)]. Other interventions for delirium were benzodiazepines in 36\% (31-42), dexmedetomidine in 21\% (17-26), quetiapine in 19\% (14-23) and olanzapine in 9\% (6-12) of the patients with delirium. In the first $24 \mathrm{~h}$ in the ICU, all subtypes of delirium [hyperactive, adjusted odds ratio (aOR) 29.7 (12.9-74.5); mixed 10.0 (5.0-20.2); hypoactive 3.0 (1.2-6.7)] and circulatory support 2.7 (1.7-4.3) were associated with haloperidol use. At $72 \mathrm{~h}$ after ICU admission, circulatory support remained associated with subsequent use of haloperidol, aOR $2.6(1.1-6.9)$. Haloperidol use within $0-24 \mathrm{~h}$ and within $0-72 \mathrm{~h}$ of ICU admission was not associated with 90-day mortality [aOR 1.2 (0.5-2.5); $p=0.66$ ] and [aOR 1.9 (1.0-3.9); $p=0.07$, respectively.
\end{abstract}

Conclusions: In our study, haloperidol was the main pharmacological agent used for delirium in adult patients regardless of delirium subtype. Benzodiazepines, other anti-psychotics and dexmedetomidine were other frequently used agents. Haloperidol use was not statistically significantly associated with increased 90-day mortality.

Keywords: Delirium, ICU, Haloperidol, Cohort, Critical care

*Correspondence: marie.oxenboell-collet@regionh.dk

1 Department of Intensive Care, Copenhagen University Hospital,

Rigshospitalet, Copenhagen, Denmark

Full author information is available at the end of the article

\section{至 Springer}




\section{Background}

Delirium in critically ill patients is a syndrome with a constellation of symptoms and neurological signs explained by pre-existing, established or evolving neurocognitive disorders. Delirium is characterised by a reduced ability to direct, focus, sustain and shift attention, reduced orientation to the environment, and disturbance in cognition, which develops over a short period of time and tends to fluctuate in severity during the course of a day [1]. The pathophysiology of delirium remains poorly understood $[2,3]$.

The observed prevalence of delirium in adult ICU patients ranges from 26 to $80 \%[4,5]$; mixed and hypoactive subtypes of delirium are more common than the hyperactive subtype [6]. The most valid and recommended monitoring tools for routine assessment of delirium in ICU are the Confusion Assessment Method (CAM-ICU) and Intensive Care Delirium Screening Checklist (ICDSC) [7].

Delirium has been associated with worse outcomes in mechanically ventilated patients [7-11] and more complications including acute respiratory distress syndrome, nosocomial pneumonia and arrhythmia [12]. Delirium in mechanically ventilated patients has been associated with up to $30 \%$ higher ICU, hospital costs and long-term cognitive impairment $[13,14]$.

The 2002 iteration of the clinical practice guidelines for the management of pain, agitation and delirium of adult patients in the ICU recommended haloperidol as the pharmacological agent for delirium [15]. However, in the 2013 update of the guideline, this recommendation was changed; haloperidol was no longer recommended for delirium in adult ICU patients due to the lack of evidence of effect [16]. The same guideline suggested that atypical antipsychotics and continuous intravenous (IV) infusion of dexmedetomidine rather than benzodiazepines may reduce the duration of delirium in ICU patients, even though these interventions also have a low level of evidence [16]. Currently, there are no pharmacological agents with solid evidence of effect on delirium; therefore, ICU clinicians must rely on their own judgement whether or not to use haloperidol or other pharmacological agents. We hypothesised that many ICU patients receive haloperidol even though clinical guidelines advice otherwise.

Our aim was to describe, in a multinational cohort of adult ICU patients, the proportion of patients intervened with haloperidol for delirium and variables associated with the use of haloperidol including delirium subtypes. We also aimed to describe the use of other pharmacological agents for delirium management in the ICU and

\section{Take-home message}

Haloperidol is, independently of delirium subtype, still the first choice for pharmacological management of delirium, followed by benzodiazepines and dexmedetomidine. Circulatory support is an additional risk factor for receiving haloperidol.

to explore the association of haloperidol with 90-day mortality.

\section{Methods}

We performed a multinational, prospective 2-week inception cohort study including 99 ICUs from Belgium, Brazil, Canada, Denmark, Finland, France, Germany, Italy, the Netherlands, Norway, Spain, Sweden and Switzerland. The study protocol was published before study conduct (http://www.cric.nu/aid-icu-national-principalinvestigators/). We use the STROBE (Strengthening the Reporting of Observational Studies in Epidemiology) statement when reporting this manuscript [17].

Each country coordinator recruited ICUs to participate within their country. Participation was voluntary and no reimbursement was given. Each participating ICU selected a 2-week period between March 7th and June 30th 2016 for patient enrolment.

\section{Study population}

All patients admitted to the participating ICUs within the 2-week inception period were screened, and those admitted acutely who were aged 18 years or older were included. Exclusion criteria were: diagnosis of mental illness including schizophrenia, psychosis or major depression; neuro-degenerative disorders such as dementia or Parkinson's disease; institutionalisation for mental illness or cognitive mental retardation; previous congenital or acquired brain damage; stroke within the last 2 weeks; ongoing seizures; suspected anoxic brain injury or acute traumatic brain injury; hospitalisation within the last 6 months for hepatic coma, drug overdose or suicide attempt; and severe vision or hearing impairment.

\section{Definitions of delirium and coma}

Several delirium screening tools were approved for the study. The patient was diagnosed as having delirium if CAM-ICU was positive [18], ICDSC was 4 or above [19], Delirium Observation Screening (DOS) was above 3 [20], or Nursing Delirium Screening Scale (Nu-DESC) was 2 or above [21] at least once a day during the ICU admission. We subtyped delirium during ICU stay as hypoactive only [lying still with open eyes and no clear contact, even with a Glasgow Coma Scale (GCS) score $\geq 8$ or Reaction Level Scale (RLS) <4] [22], hyperactive delirium 
only (agitated and non-cooperative, pulling tubes and catheters) or mixed (if both hypo- and hyperactive delirium were present during ICU stay) [6]. We defined coma as Richmond Agitation Sedation Scale (RASS) between -3 and -5 [23], Ramsay sedation score was between 4 and 6 [24], Riker Sedation-Agitation Scale (SAS) 1 and 2 [25], Motor Activity Assessment Scale (MASS) 1-0 [26], GCS score below 8 without sedation or RLS above 3 without sedation.

\section{Outcomes}

The primary outcome was the number of patients with delirium intervened with haloperidol. Secondary outcomes were the number of patients with delirium intervened with antipsychotics other than haloperidol, days alive out of ICU without coma or delirium, days alive without mechanical ventilation, and days alive out of hospital within the 90-days follow-up period. Finally, we investigated the relation between haloperidol use in the ICU and 90-day mortality.

\section{Data collection}

On ICU admission, we recorded ICU admission diagnosis, presence of known risk factors for delirium prior to hospital and ICU admission (smoking, substance, alcohol- and benzodiazepine abuse, vision and hearing impairment), and a modified Simplified Acute Physiology Score (SAPS) II [27], excluding $\mathrm{PaO}_{2} / \mathrm{FiO}_{2}$ ratio, urinary output and s-bilirubin level due to the expectation of many missing values for these variables [28]. We assessed for the presence of delirium, delirium subtype and coma, and pharmacological interventions for delirium daily. Interventions recorded included haloperidol, olanzapine, and quetiapine as milligrams per day, administrated as fixed or per needed dosage and if it was given as prophylaxis or treatment against delirium. Furthermore, we recorded if the antipsychotics were prescribed as prophylaxis or treatment. We recorded the use of dexmedetomidine at night when administrated for more than four continuous hours between $10 \mathrm{pm}$ and $6 \mathrm{am}$, the use of physical restraint, sedatives (including dexmedetomidine as continuous infusion for more than $12 \mathrm{~h}$ ), opioid infusions and sleeping medication (benzodiazepines, hypnotics and melatonin). We recorded the use of vasopressors, inotropes, mechanical ventilation and renal replacement therapy daily as binary variables. If patients were discharged to another ICU participating in the AID-ICU study, data collection was continued. If patients were readmitted to a participating ICU, data collection resumed for a maximum of 90 days. At 90 days, we obtained vital status, ICU and index hospital length of stay and additional hospital admissions during the follow-up period. Registered data were stored in a secure web-based case report form build in OpenClinica (www. openclinica.com).

\section{Ethics}

The study protocol was approved by the Danish Data Protection Agency (No. RH-2016-67, 04509) and the Danish Health and Medicines Authority (No. H-3-2014-FSP56). Each country coordinator obtained ethical approvals for the study according to national requirements.

\section{Statistical analyses}

We developed and published the statistical analysis plan prior to the closure of the study database (http://www. cric.nu/aid-icu-cohorte-study-statistical-analysis-proto $\mathrm{col} /)$.

\section{Sample size}

Based on preliminary data obtained in Copenhagen in May 2014 (the Department of Intensive Care, Rigshospitalet), where $13 \%$ of all acutely admitted adult ICU patients were intervened with haloperidol, we estimated that at least 1000 patients were needed to obtain a $95 \%$ Confidence Interval (CI) of 11-15\% around the proportion of ICU patients intervened with haloperidol.

\section{Descriptive statistics}

Categorical data were presented as numbers and percentages (\%) and medians with interquartile ranges (IQR). Chi-squared and Wilcoxon rank-sum tests were used to assess differences between patients intervened with haloperidol and those not intervened.

We conducted complete case analyses as we excluded seven patients who had incomplete data after logical imputations (ESM, Tables 1 and 2). For the 119 patients (9.4\%) with missing 90-day mortality data, we assumed they were alive and not on a ventilator, in hospital or in coma after their last registered day alive. In a supplementary analysis, we assumed that the 119 patients with missing 90-day mortality data were dead.

Patients receiving haloperidol $(n=8)$ or other antipsychotics (olanzapine $=3$, quetiapine $=9$ ) as prophylaxis who never had delirium registered during ICU admission were analysed as not having received haloperidol or other antipsychotics for delirium.

\section{Follow-up measurements and outcome analyses}

We used univariate and multiple logistic regression analysis to assess variables associated with haloperidol during ICU stay. Variables were based on information from the first $24 \mathrm{~h}$ of ICU admission and the first $72 \mathrm{~h}$ of ICU admission, respectively. Results were presented as odds ratio (ORs) with $95 \%$ CIs. In the 72 -h analysis, we included patients who were alive and still in the ICU 
$72 \mathrm{~h}$ after ICU admission and who had not received haloperidol prior to this assessment. Both the 24- and 72-h analyses were adjusted for the following predefined baseline covariates: age, delirium subtype, and use of sedation, mechanical ventilation, circulatory support or renal replacement therapy as these were expected to have low missingness and describe risk factors in general (age and use of life support) [29] and factors associated with haloperidol use (delirium subtypes). In addition, we adjusted for ICU characteristics (number of hospital beds, existence of ICU guidelines for identifying and/or using pharmacological or non-pharmacological interventions for delirium and nurse to patient ratio as $1:<1,1: 1,1:>1$ ).

Univariate and multiple logistic regression analysis were also used to assess the crude and adjusted OR $(95 \% \mathrm{CI})$ for the association between use of haloperidol in the ICU and 90-day mortality. We adjusted this analysis for the following predefined baseline covariates (at 24- and 72-h): age, delirium subtype, and use of sedation, mechanical ventilation, circulatory support or renal replacement therapy, because of expected low level of missingness and associations with mortality $[29,30]$ for the same reasons given above.

A total of five out of the 1260 patients were excluded from the follow-up analysis due to unreliable and inconsistent follow-up information that could not be fixed by logical imputations (ESM Fig. 2).

We refrained from doing the planned 1-week baseline analysis due to few patients fulfilling the outcomes $(n=27$; alive in the ICU and not exposed to haloperidol in the first week).

We performed all analyses using $\mathrm{R}$ (version 3.2 .3 ) and SAS (version 9.4), used two-tailed tests and considered $p<0.05$ to indicate statistical significance.

\section{Results}

We screened 1922 patients in the 99 ICUs from 13 countries (ESM Fig. 1 and ESM Table 2) and included 1260 patients in the analyses (ESM Fig. 2). The median length of stay in ICU was 2.9 (IQR 1.1-6.6) days.

\section{Delirium}

A total of 314 of the 1260 patients [24.9\% (95\% CI 22.627.4)] experienced delirium during the ICU stay; $13.1 \%$
(165/1260), 6.1\% (77/1260) and 5.7\% (72/1260) of all patients had mixed, hyperactive and hypoactive delirium, respectively. The median length of ICU stay for patients with delirium was 7 (IQR 3.3-14.5) days, the median number of days with delirium in the ICU was $2(1-4)$ days and the median number of days in the ICU before the onset of delirium was 3 (2-6) days.

\section{Haloperidol}

We found that $145 / 314$ [46.2\% (95\% CI 40.6-51.9)] patients with delirium were intervened with haloperidol (the primary outcome). In total, 166/1260 [13.2\% (11.4-15.2)] patients received haloperidol in the ICU. The median number of days before the first dose of haloperidol, for patients with delirium at some point during the ICU stay, was 3 (IQR 2-7) days, and the median number of days with the use of haloperidol was $2(1-5)$. The median daily and cumulative doses of haloperidol given in the ICU are presented in Table 1. Baseline patient and ICU characteristics associated with the use of haloperidol are presented in Table 2. At $24 \mathrm{~h}$, all delirium subtypes and circulatory support were associated with a higher probability of being intervened with haloperidol (Table 3). At $72 \mathrm{~h}$ after ICU admission, only circulatory support was associated with the subsequent use of haloperidol (Table 3).

\section{Other pharmacological interventions for delirium}

The most common other agents used against delirium were benzodiazepines in $36.0 \%$ (95\% CI 30.7-41.6), dexmedetomidine in $21.3 \%$ (17.2-26.2), quetiapine in $18.5 \%$ (14.3-23.2) and olanzapine in 8.6\% (5.7-12.3) of the 314 patients with delirium. Among the 145 patients with delirium that received haloperidol, benzodiazepines were by far the most commonly used second agent [44.8\% (36.6-53.3)] (Fig. 1).

\section{Mortality}

The overall 90-day mortality was $20.8 \%$ (95\% CI 18.6 23.1). After 90 days, 220 of the 1089 [20.2\% (17.8-22.7)] patients not receiving haloperidol at any time in the ICU had died compared to 41 [24.7\% (18.3-32.0)] of the 166 patients receiving haloperidol in the ICU. Among the 168 patients with delirium not intervened with haloperidol,

Table 1 Haloperidol use in milligram presented as the cumulative dose received during ICU stay and median administrated daily dose

\begin{tabular}{lccc} 
& \% Of the $\mathbf{1 2 6 0}$ patients $(\mathbf{9 5 \%} \mathrm{Cl})$ & $\begin{array}{l}\text { Median cum. dose } \\
\text { (in } \mathbf{~ m g )} \text { (IQR) }\end{array}$ & $\begin{array}{l}\text { Median daily dose } \\
\text { (in mg) (IQR) }\end{array}$ \\
\hline Haloperidol $(n=166)$ & $13.2(11.4-15.2)$ & $18(6-55)$ & $10(5-15)$ \\
As fixed dose & $9.8(8.2-11.5)$ & $12(5-46)$ & $5(3-10)$ \\
As per needed dose & $12.4(10.6-14.3)$ & $10(5-30)$ & $5(3-10)$ \\
\hline
\end{tabular}


Table 2 Baseline characteristics of all patients and stratified by use of haloperidol or not during ICU stay

\begin{tabular}{|c|c|c|c|c|}
\hline & $\begin{array}{l}\text { All patients } \\
(N=1260)\end{array}$ & $\begin{array}{l}\text { No haloperidol } \\
(N=1094)\end{array}$ & $\begin{array}{l}\text { Haloperidol } \\
(N=166)\end{array}$ & $p$-value ${ }^{b}$ \\
\hline Age (years) median (IQR) & $67(55-76)$ & $67(54-76)$ & $69(57-79)$ & 0.04 \\
\hline Male, $n(\%)$ & $779(61.8)$ & $661(60.4)$ & $118(71.1)$ & 0.01 \\
\hline \multicolumn{5}{|l|}{ Admission diagnosis, $n(\%)$} \\
\hline Sepsis & $379(30.1)$ & $301(27.5)$ & $78(47.0)$ & $<0.01$ \\
\hline Trauma & $106(8.4)$ & $93(8.5)$ & $13(7.8)$ & 0.77 \\
\hline Surgery & $443(35.2)$ & $380(34.7)$ & $63(38.0)$ & 0.42 \\
\hline Emergency surgery & $300(23.8)$ & $258(23.6)$ & $42(25.3)$ & 0.63 \\
\hline Elective surgery & $143(11.4)$ & $122(11.2)$ & $21(12.7)$ & 0.57 \\
\hline \multicolumn{5}{|l|}{ Severity score } \\
\hline SAPS $\|^{\mathrm{a}}$, median (IQR) & $32(24-42)$ & $32(23-41)$ & $37(27-47)$ & $<0.01$ \\
\hline Metastatic cancer, n (\%) & $84(6.7)$ & $80(7.3)$ & $4(2.4)$ & 0.02 \\
\hline Haematological cancer, $n(\%)$ & $66(5.2)$ & $59(5.4)$ & $7(4.2)$ & 0.53 \\
\hline AIDS, $n(\%)$ & $14(1.1)$ & $13(1.2)$ & $1(0.1)$ & 0.50 \\
\hline \multicolumn{5}{|l|}{ Prior to ICU admission } \\
\hline Haloperidol, $n$ (\%) & $32(2.5)$ & $14(1.3)$ & $18(10.8)$ & $<0.01$ \\
\hline Smoking, $n(\%)$ & $307(24.4)$ & $258(23.6)$ & $49(29.5)$ & 0.10 \\
\hline Alcohol abuse, $n(\%)$ & $153(12.1)$ & $129(11.8)$ & $24(14.5)$ & 0.33 \\
\hline Substance abuse, $n$ (\%) & $32(2.5)$ & $27(2.5)$ & $5(3.0)$ & 0.68 \\
\hline Benzodiazepines, n (\%) & $134(10.6)$ & $108(9.9)$ & $26(15.7)$ & 0.02 \\
\hline Vision impaired, $n(\%)$ & $261(20.7)$ & $219(20.0)$ & $42(25.3)$ & 0.12 \\
\hline Hearing impaired, $n$ (\%) & $72(5.7)$ & $59(5.4)$ & $13(7.8)$ & 0.21 \\
\hline \multicolumn{5}{|l|}{ First 24-h in ICU admission } \\
\hline In coma, $n(\%)$ & $479(38.0)$ & $390(35.7)$ & $89(53.6)$ & $<0.01$ \\
\hline Delirium $^{\mathrm{b}}, n(\%)$ & $125(9.9)$ & $71(6.5)$ & $54(32.5)$ & $<0.01$ \\
\hline Mechanical ventilation, $n(\%)$ & $702(55.7)$ & $581(53.1)$ & $121(72.9)$ & $<0.01$ \\
\hline Circulatory support, n (\%) & $569(45.2)$ & $453(41.4)$ & $116(70.1)$ & $<0.01$ \\
\hline Renal replacement therapy, $n$ (\%) & $105(8.3)$ & $86(7.9)$ & $19(11.5)$ & 0.12 \\
\hline
\end{tabular}

a Modified Simplified Acute Physiology Score (SAPS) II as oxygenation, s-bilirubin and urinary output was not included

b Comparisons of the groups no use of haloperidol vs. use of haloperidol in ICU by Chi-squared or Wilcoxon rank-sum (age and SAPS II) tests. Patients receiving haloperidol or other antipsychotics as prophylaxis without delirium during ICU admission $(n=8)$ were not included in the haloperidol group

$22.6 \%(16.5-29.7)$ had died at 90-day follow-up as compared with $22.1 \%(15.6-29.7)$ among the 145 patients with delirium intervened with haloperidol at some point during ICU stay. The crude and adjusted associations between use of haloperidol within the first 24- and 72-h and 90-day mortality are presented in Fig. 2.

\section{Other outcomes}

The median number of days alive without mechanical ventilation, days alive without coma or delirium, days alive out of ICU, and days out of hospital within 90-days are presented in ESM Table 5. A total of 217/1260 patients $(17.2 \%)$ were at some point physically restrained during ICU stay.

\section{Discussion}

In this multinational, 2-week inception cohort study, we observed that $12 \%$ of acutely admitted adult ICU patients received haloperidol for delirium. Regardless of subtypes (hyperactive, mixed and hypoactive) delirium was associated with a markedly increased odds of receiving haloperidol. Also, circulatory support was a risk factor for the use of haloperidol. The use of haloperidol within the first 24 or $72 \mathrm{~h}$ of ICU admission was not associated with 90-day mortality in either the crude or adjusted analyses. Other commonly used agents against delirium in the ICU patients were benzodiazepines, other antipsychotics and dexmedetomidine.

We found that the overall use of haloperidol was $13 \%$. The difference between the overall use of haloperidol and patients with delirium received haloperidol, might be due to patients in coma receiving haloperidol for delirium or that there may be a difference in how patients were perceived as having delirium by clinicians. A similar study also found an association between use of antipsychotics in the ICU and delirium [31]. 
Table 3 Association between characteristics within the first 24 and $72 \mathrm{~h}$ of ICU admission and the subsequent use of haloperidol in ICU

\begin{tabular}{|c|c|c|c|c|}
\hline & \multicolumn{2}{|c|}{ Characteristics in the first $24 \mathrm{~h}$ of ICU admission } & \multicolumn{2}{|c|}{$\begin{array}{l}\text { Characteristics in the first } 72 \mathrm{~h} \text { of ICU admis- } \\
\text { sion }\end{array}$} \\
\hline & \multicolumn{2}{|l|}{$1255^{\mathrm{a}}$ Patients } & \multicolumn{2}{|l|}{$504^{\mathrm{b}}$ Patients } \\
\hline & Crude OR (95\% CI) & Adjusted ${ }^{c}$ OR $(95 \% \mathrm{Cl})$ & Crude OR $(95 \% \mathrm{CI})$ & Adjusted ${ }^{c}$ OR ( $\left.95 \% \mathrm{Cl}\right)$ \\
\hline \multicolumn{5}{|l|}{ Delirium } \\
\hline No & 1 (ref) & 1 (ref) & 1 (ref) & 1 (ref) \\
\hline Hyperactive & $15.6(7.9-31.8)$ & $29.7(12.9-74.5)$ & $0.9(0.1-3.3)$ & $1.2(0.2-5.5)$ \\
\hline Hypoactive & $3.1(1.4-6.4)$ & $3.0(1.2-6.7)$ & $0.2(.01-1.1)$ & $0.2(.01-1.1)$ \\
\hline Mixed delirium & $6.7(3.6-12.4)$ & $10.0(5.0-20.2)$ & $0.8(0.2-2.2)$ & $1.2(0.3-4.1)$ \\
\hline Coma & $2.1(1.5-2.9)$ & - & $4.7(2.4-10.4)$ & - \\
\hline Renal replacement therapy & $1.5(0.8-2.5)$ & $1.0(0.5-1.7)$ & $1.5(0.7-2.8)$ & $1.1(0.5-2.2)$ \\
\hline Circulatory support & $3.3(2.3-4.7)$ & $2.7(1.7-4.3)$ & $4.8(2.3-11.7)$ & $2.6(1.1-6.9)$ \\
\hline Mechanical ventilation & $2.4(1.7-3.5)$ & $1.5(0.9-2.6)$ & $7.5(2.7-31.2)$ & $3.0(0.9-14.2)$ \\
\hline Sedation & $2.6(1.9-3.6)$ & $1.4(0.9-2.3)$ & $4.3(2.2-9.6)$ & $1.9(0.8-5.0)$ \\
\hline \multicolumn{5}{|l|}{ Age (years) } \\
\hline $18-49$ & 1 (ref) & 1 (ref) & 1 (ref) & 1 (ref) \\
\hline $50-59$ & $1.7(1.0-3.1)$ & $1.4(0.7-2.6)$ & $1.0(0.4-2.2)$ & $1.0(0.4-2.4)$ \\
\hline $60-74$ & $1.1(0.7-2.0)$ & $0.6(0.4-1.3)$ & $0.5(0.2-1.0)$ & $0.4(0.2-0.9)$ \\
\hline $75+$ & $1.8(1.1-3.0)$ & $1.2(0.7-2.1)$ & $0.7(0.3-1.5)$ & $0.6(0.2-1.3)$ \\
\hline \multicolumn{5}{|l|}{ Nurse to patient ratio ${ }^{d}$} \\
\hline $1:>1$ & 1 (ref) & 1 (ref) & 1 (ref) & 1 (ref) \\
\hline 1:1 & $1.8(1.2-2.8)$ & $1.8(1.1-3.0)$ & $2.0(1.0-3.9)$ & $1.7(0.7-3.6)$ \\
\hline $1:<1$ & $1.1(0.5-2.0)$ & $1.4(0.6-3.0)$ & $1.5(0.4-2.2)$ & $2.2(0.9-4.3)$ \\
\hline Guideline to identify delirium $^{d}$ & $1.0(0.6-1.4)$ & $1.3(0.7-2.3)$ & $1.2(0.7-2.2)$ & $2.2(0.9-5.3)$ \\
\hline Guideline to treat delirium (pharma) $^{d}$ & $0.7(0.5-1.0)$ & $0.6(0.3-1.2)$ & $0.9(0.5-1.5)$ & $0.5(0.2-1.4)$ \\
\hline Guideline to treat delirium (non-pharma) $^{d}$ & $1.2(0.9-1.7)$ & $1.6(1.0-2.6)$ & $1.4(0.8-2.5)$ & $1.7(0.8-3.6)$ \\
\hline \multicolumn{5}{|l|}{ Number of hospital beds ${ }^{d}$} \\
\hline $0-249$ & 1 (ref) & 1 (ref) & 1 (ref) & 1 (ref) \\
\hline 250-499 & $2.5(1.1-6.7)$ & $1.6(0.6-4.9)$ & $4.4(0.9-81.1)$ & $3.1(0.5-60.9)$ \\
\hline 500-999 & $3.5(1.6-9.3)$ & $1.5(0.6-4.6)$ & $8.3(1.7-150.3)$ & $4.0(0.7-76.9)$ \\
\hline $1000+$ & $2.5(1.1-6.7)$ & $1.6(0.6-4.8)$ & $6.0(1.2-109.6)$ & $3.2(0.6-60.3)$ \\
\hline
\end{tabular}

Univariate and multiple logistic regressions analysis was performed with crude and adjusted odds ratios (ORs) with $95 \%$ confidence intervals (Cls). Patients receiving haloperidol or other antipsychotics as prophylaxis with no delirium during ICU admission were excluded from the treatment group

a Five patients were excluded due to unreliable and inconsistent follow-up data

b In the $72 \mathrm{~h}$ analysis, we included patients who were alive in the ICU if they had not received haloperidol prior to this assessment

c Adjusted for the following pre-defined baseline covariates: age, delirium subtype, use of dialysis, circulatory support, mechanical ventilation or sedation, and ICU characteristics (nurse to patient ratio, guidelines to identify delirium, guidelines to treat delirium, guidelines (non-pharma) to treat delirium and number of hospitals beds)

d 47 patients did not contribute to the adjusted analysis due to missing values

The reported prevalence of delirium in our study was $25 \%$, which may be lower than in previous reports with rates of $40 \%$ in non-mechanical ventilated patients and $60 \%$ of mechanically ventilated patients $[32,33]$. The higher rate reported in previous studies may be attributed to the fact that they excluded patients not expected to be in the ICU more than $24 \mathrm{~h}$ and only included mechanically ventilated patients. Both duration of ICU stay and mechanical ventilation are known risk factors for delirium in critically ill patients. Also, we used a more conservative definition of coma as RASS -3 to -5 , hence delirium was not registered in these patients. This is similar to the findings by Haenggi and colleagues in 2013 where the rate of delirium decreased when excluding patients with RASS -2 to -3 [34].

In the present study, the modified SAPS II at admission was higher in patients receiving haloperidol than in those who did not. We used modified SAPS II at admission and 


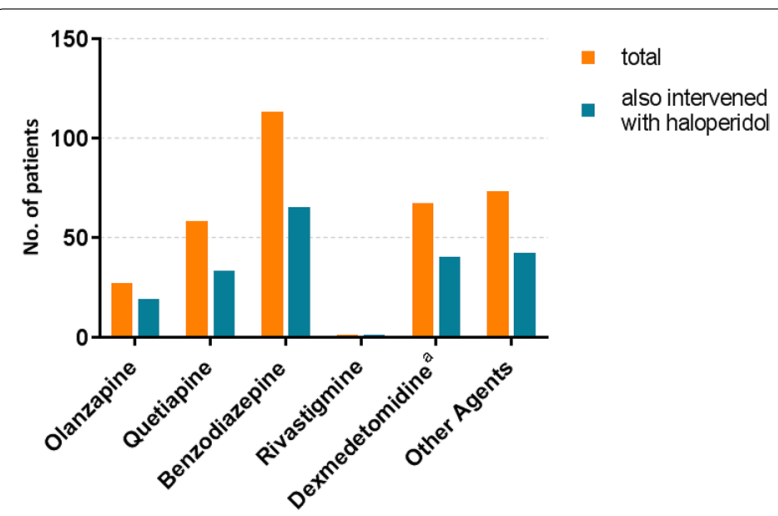

Fig. 1 Patients with delirium intervened with other antipsychotics, benzodiazepines and dexmedetomidine either alone or in combination with haloperidol. Other agents include other sedatives. ${ }^{\text {aD }}$ exmedetomidine used for more than four consecutive hours between $10 \mathrm{pm}$ and $6 \mathrm{am}$

found a lower score than in other similar cohort studies [28]. According to our predefined statistical analysis plan, we did not adjust for the modified SAPS II, but chose variables with expected complete data (age, mechanical ventilation, circulatory support and renal replacement therapy) due to an expected missingness of more than
$20 \%$ of especially s-bilirubin and urinary output at ICU admission in SAPS II [29]. In addition, age and use of life support are important risk factors for poor outcome among ICU patients $[29,35]$.

The strengths in this study include the prospective design using a 2-week inception period with the inclusion of a large number of patients from multiple ICUs in numerous countries, the pre-specified and published protocol and statistical analysis plan, the handling and reporting of missing data, and the adjustments for known potential confounders. Consequently, we believe that these results have high internal and external validity.

The limitations of this study include the observational design, which has the inherent risk of confounding by indication and residual confounding. Moreover, $40 \%$ of the participating ICUs were Danish or Spanish and the results may be influenced by national practice and guidelines in these countries. Participation was voluntary and not selected to be representative of all ICUs, consequently, the ICUs might differ from those declining and those not invited. For delirium detection, we used a pragmatic approach; there were no requirements for use of a specific tool for delirium detection. Tools that are not yet validated in ICU patients may have been used at some sites thereby affecting the observed delirium incidence.

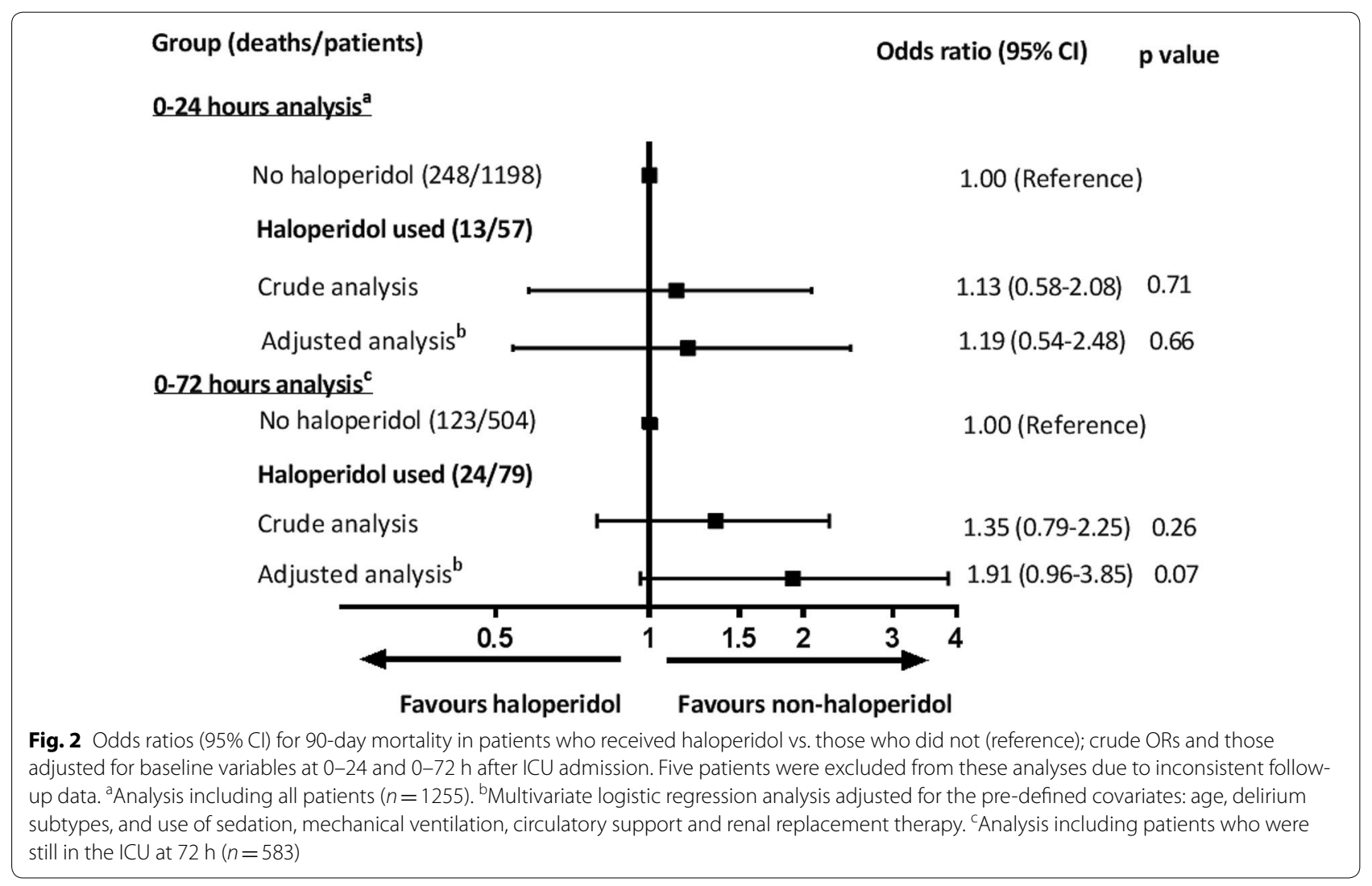


We did not pilot test the definitions of delirium subtypes and some misclassification might have occurred. We did not collect data on the potential harm associated with the use of haloperidol, including extrapyramidal symptoms [36], tardive dyskinesia, cardiovascular effects [37] and neuroleptic malignant syndrome [38]. Finally, delirium is defined as fluctuating and one delirium score per day does not necessarily identify all those patients developing this organ failure. We had missing data for mortality for 119 who were discharged alive and assumed that these were alive at 90-days. In our "worst case" sensitivity analysis assuming that they were all dead at day 90 , the use of haloperidol was associate with increased 90-day mortality. Therefore, we cannot exclude entirely that there might be an association.

In contrast to previous findings [39], we did not find that haloperidol in the entire cohort was associated with improved survival. This might be due to differences between the study cohorts. We believe that the effects of haloperidol on mortality and other important outcomes can only be assessed in a randomised clinical trial (RCT). Such RCTs are warranted as we found a high frequency of the use of haloperidol in our ICU patients with delirium, a finding supported by those of another recent cohort study [40]. Combined with our finding of a $25 \%$ prevalence of delirium in ICU patients, there is a pressing need for RCTs assessing the overall benefits and harms of the use of haloperidol in these patients.

\section{Conclusions}

In this multinational, prospective cohort study of acutely admitted adult ICU patients, we observed that haloperidol was the most common pharmacological intervention for delirium independent of delirium subtype. Benzodiazepine, quetiapine, dexmedetomidine and olanzapine were also used in ICU patients with delirium. At the 5\% statistical significance level, we did not observe that the use of haloperidol was associated with increased 90-day mortality.

\section{Electronic supplementary materia}

The online version of this article (https://doi.org/10.1007/s00134-018-5204-y) contains supplementary material, which is available to authorized users.

\footnotetext{
Author details

1 Department of Intensive Care, Copenhagen University Hospital, Rigshospitalet, Copenhagen, Denmark. ${ }^{2}$ Centre for Research in Intensive Care, Copenhagen, Denmark. ${ }^{3}$ Hospital Universitari Arnau de Vilanova de Lleida-IRBLleida, Hospital Universitari Vall d'Hebron-VHIR, Universitat Autònoma de BarcelonaUAB, Barcelona, Spain. ${ }^{4}$ Department of Intensive Care Medicine and Infectious Diseases, Bichat Claude Bernard Hospital, AP-HP, Paris, France. ${ }^{5}$ UMR1 148, LVTS, Sorbonne Paris Cité, Inserm/Paris Diderot University, Paris, France. ${ }^{6}$ National Institute of Infectious Disease, Oswaldo Cruz Foundation, Ministry of Health, Rio de Janeiro, Brazil. ${ }^{7}$ Department of Nursing Research, University Hospital of Schleswig-Holstein, Kiel, Germany. ${ }^{8}$ Department of Anaesthesiology and Intensive Care Medicine, University Hospital of Schleswig-Holstein, Kiel, Germany. ${ }^{9}$ Department of Perioperative Medicine and Intensive Care,
}

Karolinska University Hospital, Stockholm, Sweden. ${ }^{10}$ Division of Emergencies and Intensive Care, Oslo University Hospital, Oslo, Norway. ${ }^{11}$ Neuroanaesthesia and Neurointensive Care, School of Medicine and Surgery, H San Gerardo Monza, University of Milano Bicocca, Milan, Italy. ${ }^{12}$ Department Intensive Care Medicine, Radboud University Medical Center, Nijmegen, The Netherlands.

${ }^{13}$ Division of Intensive Care, Department of Anaesthesia, Intensive Care and Pain Medicine, University of Helsinki and Helsinki University Hospital, Helsinki, Finland. ${ }^{14}$ Department of Intensive Care Medicine, University Hospital Bern, Inselspital, University of Bern, Bern, Switzerland. ${ }^{15}$ Intensive Care Unit, University Hospital Gent, Ghent, Belgium. ${ }^{16}$ Department of Critical Care Medicine, Sunnybrook Health Sciences Centre, Toronto, ON, Canada. ${ }^{17}$ Florence Nightingale Faculty of Nursing, Midwife and Palliative Care, King's College London, London, UK. ${ }^{18}$ Copenhagen Trial Unit, Copenhagen University Hospital, Rigshospitalet, Copenhagen, Denmark. ${ }^{19}$ Department of Public Health, Section of Biostatistics, University of Copenhagen, Copenhagen, Denmark.

${ }^{20}$ Department of Intensive Care, University Hospital Aarhus, Aarhus, Denmark.

${ }^{21}$ Centre for Statistical Science, Peking University, Beijing, China.

\section{Acknowledgements}

The AID-ICU cohort study investigators are listed in the ESM.

\section{Funding information}

The AID-ICU study is funded by the Innovation Foundation Denmark.

\section{Compliance with ethical standards}

\section{Conflicts of Interest}

The ICU at Rigshospitalet has received support for research from Fresenius Kabi, CSL Behring and Ferring Pharmaceuticals. The ICU at Bern University Hospital has received support from Orion Corporation, Abbott Nutrition International, B. Braun Medical AG, CSEM SA, Edwards Lifesciences Services GmbH/ SA, Kenta Biotech Ltd, Maquet Critical Care AB, Omnicare Clinical research AG and Nestlé. Same ICU department received educational grants from Fresenius Kabi, GSK, MSD, Lilly, Baxter, Astellas, AstraZeneca, B. Braun Medical AG, CSL Behring, Maquet, Novartis, Covidien, Nycomed, Pierre Fabre Pharma (Robe Pharma), Pfizer, and Orion Pharma. Author Jesus Caballero has received funds from Astellas, Medtronic, Sedana Medical, Orion Pharma, Pfizer and Brinda Healthcare.

Received: 6 February 2018 Accepted: 30 April 2018

Published online: 16 May 2018

\section{References}

1. Boustani M, Rudolph J, Shaughnesse M (2014) The DSM-5 criteria, level of arousal and delirium diagnosis: inclusiveness is safer. BMC Med 12:141. https://doi.org/10.1186/s12916-014-0141-2

2. Slooter AJC, Van De Leur RR, Zaal IJ (2017) Delirium in critically ill patients. Handb Clin Neurol 141:449-466. https://doi.org/10.1016/B978-0-44463599-0.00025-9

3. Gunther ML, Morandi A, Ely EW (2008) Pathophysiology of delirium in the intensive care unit. Crit Care Clin 24:45-65. https://doi.org/10.1016/j. ccc.2007.10.002

4. Hipp DM, Ely EW (2012) Pharmacological and nonpharmacological management of delirium in critically ill patients. Neurotherapeutics 9:158-175. https://doi.org/10.1007/s13311-011-0102-9

5. Kanova M, Sklienka P, Roman K, Burda M, Janoutova J (2017) Incidence and risk factors for delirium development in ICU patients - a prospective observational study. Biomed Pap 161:187-196. https://doi.org/10.5507/ bp.2017.004

6. Peterson JF, Pun BT, Dittus RS, Thomason JW, Jackson JC, Shintani AK, Ely EW (2006) Delirium and its motoric subtypes: a study of 614 critically ill patients. J Am Geriatr Soc 54:479-484. https://doi.org/10.111 1/j.1532-5415.2005.00621.x

7. Kalabalik J, Brunetti L, El-Srougy R (2014) Intensive care unit delirium: a review of the literature. J Pharm Pract 27:195-207. https://doi. org/10.1177/0897190013513804 
8. Han HJ, Shintani A, Eden S, Morandi A, Solberg LM, Schnelle J, Dittus RS, Storrow AB, Ely EW (2010) Delirium in the emergency department: an independent predictor of death within 6 months. Ann Emerg Med 56:244-252. https://doi.org/10.1016/j.annemergmed.2010.03.003

9. Salluh JI, Soares M, Teles JM et al (2010) Delirium epidemiology in critical care (DECCA): an international study. Crit Care 14:R210. https://doi. org/10.1186/cc9333

10. Lat I, McMillian W, Taylor S, Janzen JM, Papadopoulos S, Korth L, Ehtisham A, Nold J, Aqarwai S, Azocar R, Burke P (2009) The impact of delirium on clinical outcomes in mechanically ventilated surgical and trauma patients. Crit Care Med 37:1898-1905. https://doi.org/10.1097/ CCM.0b013e31819ffe38

11. Pandharipande PP, Girad TD, Jackson JC et al (2013) Long-term cognitive impairment after critical illness. New Engl J Med 369:1306-1316. https:/ doi.org/10.1056/NEJMoa1301372

12. Zhang Z, Pan L, Ni H (2013) Impact of delirium on clinical outcome in critically ill patients: a meta-analysis. Gen Hosp Psychiatry 35:105-111. https://doi.org/10.1016/j.genhosppsych.2012.11.003

13. Milbrandt EB, Deppen S, Harrison PL, Shintani AK, SperoffT, Stiles RA, Truman B, Bernard GR, Dittus RS, Ely EW (2004) Costs associated with delirium in mechanically ventilated patients. Crit Care Med 32:955-962

14. Sakusic A, O'Horo JC, Dziadzko M, Volha D, Ali R, Singh TD, Kashyap R, Farrell AM, Fryer JD, Petersen R, Gajic O, Rabinstein AA (2018) Potentially modifiable risk factors for long-term cognitive impairment after critical illness: a systematic review. Mayo Clin Proc 93:68-82. https://doi. org/10.1016/j.mayocp.2017.11.005

15. Jacobi J, Fraser GL, Coursin DB et al (2002) Clinical practice guidelines for the sustained use of sedatives and analgesics in the critically ill adult. Crit Care Med 30:119-141

16. Barr J, Fraser GL, Puntillo K et al (2013) Clinical practice guidelines for the management of pain, agitation, and delirium in adult patients in the intensive care unit. Crit Care Med 41:263-306. https://doi.org/10.1097/ cCM.0b013e3182783b72

17. von Elm E, Altman DG, Egger M, Pocock SJ, Gøtzsche PC, Vandenbroucke JP (2008) The strengthening the reporting of observational studies in epidemiology (STROBE) statement: guidelines for reporting observational studies. J Clin Epidemiol 61:344-349. https://doi.org/10.1016/j. ijsu.2014.07.013

18. Ely EW, Margolin R, Francis J, May L, Truman B, Dittus R, Speroff T, Gautam S, Bernard GR, Inouye SK (2001) Evaluation of delirium in critically ill patients: validation of the confusion assessment method for the intensive care unit (CAM-ICU). Crit Care Med 29:1370-1379

19. Marquis F, Ouimet S, Riker R, Cossette M, Skrobik Y (2007) Individual delirium symptoms: do they matter? Crit Care Med 35:2533-2537

20. Schuurmans MJ, Shortridge-Baggett LM, Duursma SA (2003) The delirium observation screening scale: a screening instrument for delirium. Res Theory Nurs Pract 17:31-50

21. Gaudreau JD, Gagnon P, Harel F, Tremblay A, Roy MA (2005) Fast, systematic, and continuous delirium assessment in hospitalized patients: the nursing delirium screening scale. J Pain Symptom Manag 29:368-375. https://doi.org/10.1016/j.jpainsymman.2004.07.009

22. Starmark JE, Stålhammar D, Holmgren E (1988) The reaction level scale (RLS85), manual and guidelines. Acta Neurochir (Wien) 91:12-20

23. Sessler CN, Gosnell MS, Grap MJ, Brophy GM, O'Neal PV, Keane KA, Tesoro EP, Elswick RK (2002) The richmond agitation-sedation scale. Am J Respir Crit Care Med 166:1338-1344. https://doi.org/10.1164/rccm.2107138

24. Sessler CN, Grap MJ, Ramsay MA (2008) Evaluating and monitoring analgesia and sedation in the intensive care unit. Crit Care 12:S2. https://doi. org/10.1186/cc6148

25. Riker RR, Picard JT, Fraser GL (1999) Prospective evaluation of the sedation-agitation scale for adult critically ill patients. Crit Care Med 27:1325-1329
26. Devlin JW, Boleske G, Mlynarek M, Nerenze DR, Peterson E, Jankowski M, Horst HM, Zarowitz BJ (1999) Motor activity assessment scale: a valid and reliable sedation scale for use with mechanically ventilated patients in an adult surgical intensive care unit. Crit Care Med 27:1271-1275

27. Le Gall JR, Lemeshow S, Saulnier F (1993) A new simplified acute physiology score (SAPS II) based on a European/North American multicenter study. JAMA 270:2957-2963

28. Krag M, Perner A, Wetterslev J, Wise MP, Borthwick M, Bendel S, McArthur C, Cook D, Nielsen N, Pelosi P, Keus F, Guttormsen AB, Moller AD, Møller $\mathrm{MH}$ (2015) Prevalence and outcome of gastrointestinal bleeding and use of acid suppressants in acultely ill adult intensive care patients. Intensive Care Med 41:833-845. https://doi.org/10.1007/s00134-015-3725-1

29. Granholm A, Perner A, Krag M, Hjortrup PB, Haase N, Holst LB, Marker S, Collet MO, Jensen AKG, Møller MH (2018) Development and internal validation of the simplified mortality score for the intensive care unit (SMSICU). Acta Anaesthesiol Scand 62:3. https://doi.org/10.1111/aas.13048

30. Strøm T, Martinussen T, Toft P (2010) A protocol of no sedation for critically ill patients receiving mechanical ventilation: a randomised trial. Lancet 375:475-480. https://doi.org/10.1016/S0140-6736(09)62072-9

31. Burry LD, Williamson DR, Metha S, Perreault MM, Mantas I, Mallick R, Fergusson DA, Smith O, Fan E, Dupuis S, Herridge M, Rose L (2017) Delirium and exposure to psychoactive medications in critally ill adults: a multi-centre observational study. J Crit Care 42:268-274. https://doi. org/10.1016/j.jcrc.2017.08.003

32. Ely EW, shintani A, Truman B, Speroff T, Gordon SM, Harrell FR Jr, Inouye SK, Bernard GR, Dittus RS (2004) Delirium as a predictor of mortality in mechanically ventilated patients in the intensive care unit. J Am Med Assoc 14:1753-1762. https://doi.org/10.1001/jama.291.14.1753

33. Pisani MA, Araujo KLB, Murphy TE (2015) Association of cumulative dose of haloperidol with next day delirium in older medical intensive care unit patients. Crit Care Med 43:996-1002. https://doi.org/10.1097/CCM.00000 00000000863

34. Haenggi M, Blum S, Brechbuehl R, Brunello A, Jakob SM, Takala J (2013) Effect of sedation level on the prevalence of delirium when assessed with CAM-ICU and ICDSC. Intensive Care Med 39:2171-2179. https://doi. org/10.1007/s00134-013-3034-5

35. Meyhoff TS, Krag M, Hjortrup PB, Perner A, Møller MH (2017) Use of life support in acutely admitted ICU patients. An international cohort study. Acta Anaesthesiol Scand 61:513-522. https://doi.org/10.1111/aas.12878

36. Schrijver EJM, de Graaf K, de Vries OJ, Maier AB, Nanayakkara PW (2016) Efficacy and safety of haloperidol for in-hospital delirium prevention and treatment: a systematic review of current evidence. Eur J Intern Med 27:14-23. https://doi.org/10.1016/j.ejim.2015.10.012

37. Duprey MS, Al-Qadheeb N, Roberts R, Skrobik Y, Schumaker G, Devlin JW (2016) The use of low-dose IV haloperidol is not associated with QTC prolongation: post hoc analysis of a randomized, placebo-controlled trial. Intensive Care Med 42:1818-1819. https://doi.org/10.1007/s0013 4-016-4512-3

38. Berman BD (2011) Neuroleptic malignant syndrome: a review for neurohospitalists. Neurohospitalist 1:41-47. https://doi.org/10.1177/19418 75210386491

39. Milbrandt EB, Kersten A, Kong L, Weissfeld LA, Clermont G, Fink MP, Angus DC (2005) Haloperidol use is associated with lower hospital mortality in mechanically ventilated patients. Crit Care Med 33:226-229

40. Thiboutot Z, Perreault MM, Williamson DR, Rose L, Mehta S, Guenette MD, Cook D, Burry L (2016) Antipsychotic drug use and screening for delirium in mechanically ventilated patients in canadian intensive care units: an observational study. Can J Hosp Pharm 69:107-113 